\title{
A concepção dos pacotes turísticos para o Circuito da Fé do Brasil: entre a comercialização e a experiência da fé
}

\section{The conception of packages for Faith Circuit in Brazil: between the profit and faith experience}

\author{
Juliana Ribeiro Tomaz da Silva Nunes (NUNES, J. R. T. da S.) \\ Ana Paula Guimarães Santos de Oliveira (OLIVEIRA, A. P. G. S. de) ${ }^{* *}$
}

RESUMO - O Turismo Religioso estimula a economia de mais de 300 cidades no Brasil, sendo a maioria delas localizadas no interior do país. Tendo em vista essa representatividade objetivou-se compreender a relação entre o lucro e a experiência da fé na concepção dos pacotes turísticos com destino ao Circuito Turístico Religioso localizado no Vale do Paraíba - interior de São Paulo (Brasil). A pesquisa estruturou-se sob a abordagem quantitativa e qualitativa, e se recorreu à pesquisa bibliográfica e à de campo para o estabelecimento de análise comparativa entre as motivações de um turista religioso e os serviços oferecidos pelas agências. A análise foi estruturada a partir de seis variáveis (Escolha da categoria dos hotéis e pousadas; Preparação espiritual e reflexiva para a viagem; Tempo destinado ao lazer; Momentos solitários e em grupo; Interação com a comunidade local e Tempo para a visita nos lugares sagrados). Como resultado, destaca-se que os pacotes se encontram em uma fase de transição - entre uma concepção pautada na comercialização e outra voltada para a experiência - sendo considerados alguns aspectos importantes relacionados com a experiência da fé e outras motivações desejadas pelos turistas.

Palavras-chave: Turismo Religioso; Comercialização; Experiência; Fé; Motivações.

ABSTRACT - The Religious Tourism stimulates the economy of more than 300 cities in Brazil, being most of them located in the country region. Observing this representation, this study aimed to understand the relationship between the profit and faith experience in the conception of tourist packages with destination to the Faith Circuit located in Vale do Paraíba - country region of São Paulo. The research was structured under the quantitative and qualitative approach, and used both, bibliographic and field research to the establishment of the comparative analysis between the motivation of a religious tourist and the services offered by the agencies. The analysis was structured on top of six variables (the choice of hotel categories; Spiritual and reflective preparation for the trip; Time for leisure; Solitary and in group moments; Interaction with the local community and time to visit holy places). As a result, stands

\footnotetext{
* Formação: Graduação (Bacharelado) em Planejamento Integrado do Turismo pela Universidade Federal de Minas Gerais (UFMG). Atividade profissional: Gerente Executiva no Macaé Convention \& Visitors Bureau. Endereço físico para correspondência: Avenida Rui Barbosa, $270-3^{\circ}$ andar (Centro). CEP: 27910-361 - Macaé (Rio de Janeiro) - Brasil. / Telefone: (22) 2759-2260. E-mail: julianaribeirots@gmail.com

** Formação: Graduação em Turismo pelas Faculdades Integradas Newton Paiva, Especialização em Gestão Estratégica de Marketing pelo Unicentro Newton Paiva, Mestrado em Administração pela FEAD/Minas. Atividade profissional: Professora Assistente - Universidade Federal de Minas Gerais (UFMG.). Endereço físico para correspondência: Av. Antônio Carlos, 6627 (Pampulha). CEP: 31270-901 - Belo Horizonte (Minas Gerais) - Brasil. E-mail: anapaulagsantos@yahoo.com.br
} 
out the fact that the packages are in a transition phase - between a marketing conception and in other focused in experience - being considered some important aspects related to faith experience and other motivation wished upon by the tourists.

Key words: Religious Tourism; Profit; Experience; Faith; Motivation. 


\section{INTRODUÇÃO}

A busca do ser humano pelo seu centro espiritual - o seu self - o motiva a se deslocar a lugares onde ele acredita que terá as suas necessidades interiores sanadas (Adaptado de PELLEGRINI, 1997). Como uma das consequências dessa busca surge o turismo religioso que é originado de uma procura espiritual e da prática religiosa em ambientes e eventos relacionados às religiões institucionalizadas, independentemente da origem étnica ou do credo (BRASIL, 2010, p. 19).

No Brasil, o Turismo Religioso estimula a economia de mais de 300 cidades, sendo a maioria delas localizadas no interior do país. $(\mathrm{G} 1,2010)^{1}$. Foram identificados pelo governo federal, 344 municípios com calendário de eventos, sendo a maior parte deles, alinhados à religião católica $(\mathrm{G} 1,2010)^{2}$. De acordo com a pesquisa realizada pela Fundação Instituto de Pesquisas Econômicas (FIPE) 8,1 milhões de viagens domésticas motivadas pela fé ocorrem durante o ano, o que representa 3,6\% de todas as viagens realizadas dentro do país (CURY, 2010 apud G1, 2010) ${ }^{3}$.

No território brasileiro, os principais destinos para a prática do turismo religioso provêm da religião católica. O "Círio da Nossa Senhora de Nazaré" em Belém (Pará/PA), "Juazeiro do Norte" no Vale do Cariri (Ceará/CE) e as cidades de Aparecida e Guaratinguetá no interior do Estado de São Paulo estão entre os principais destinos que atraem uma demanda elevada de turistas movidos pela fé católica. $(\mathrm{G} 1,2010)$

Tendo em vista a posição de destaque representada pelo Turismo Religioso no Brasil, o presente estudo nasceu da inquietude em compreender como as empresas que estavam oferecendo pacotes ligados ao turismo religioso comercializavam seus produtos. O escopo foi descobrir se a base para a formatação de pacotes turísticos estava fundamentada na experiência do viajante ou apenas nos interesses econômicos que a prática pode oferecer aos empreendimentos.

\footnotetext{
${ }^{1}$ Disponível em: <http://g1.globo.com/economia-e-negocios/noticia/2010/09/turismo-religioso-estimulaeconomia-de-mais-de-300-cidades-do-pais.html>. Acesso em: 6/12/ 2011.

2 Disponível em: http://g1.globo.com/economia-e-negocios/noticia/2010/09/turismo-religioso-estimulaeconomia-de-mais-de-300-cidades-do-pais.html . Acesso em: 6/12/ 2011.

3 CURY, A. Turismo religioso estimula economia de mais de $\mathbf{3 0 0}$ cidades do país. Disponível em: http://g1.globo.com/economia-e-negocios/noticia/2010/09/turismo-religioso-estimula-economia-de-mais-de-300-cidades-dopais.html. Acesso em: 05/12/2011.
} 
A escolha dos destinos pesquisados foi fundamentada pela alta representatividade que o Circuito turístico da Fé desempenha, uma vez que ele recebe, segundo o Serviço Brasileiro de Apoio às Micro e Pequenas Empresas - SEBRAE ${ }^{4}$, cerca de 10 milhões de visitantes anualmente. O circuito é composto pelas cidades de Aparecida, Guaratinguetá, Cachoeira Paulista, Lorena e Canas, sendo as duas últimas incorporadas recentemente ao circuito. (SEBRAE, 2013) ${ }^{5}$.

Assim sendo, surgiu a seguinte hipótese: Os pacotes turísticos com destinos às cidades do Circuito da Fé do Brasil são concebidos pelo viés econômico e não pela perspectiva da experiência da fé. Como forma de alcançar uma conclusão elaborou-se a seguinte problemática: As empresas que estavam promovendo viagens para o Circuito da Fé levavam em conta a experiência que um turista religioso desejava obter para a formatação de seus pacotes turísticos? Para responder ao questionamento e a hipótese levantada, o objetivo principal da pesquisa foi o de analisar a relação entre a concepção dos pacotes turísticos e a experiência da fé para o Circuito Turístico Religioso do Vale do Paraíba - SP.

Assim sendo, buscou-se ainda conhecer as características mais marcantes no comportamento do turista religioso a partir do diagnóstico do seu perfil; Observar qual das tipologias inerentes ao turista religioso se sobressaíam e analisar se estaria havendo uma internalização do conceito da "Economia da Experiência" por parte das agências e operadoras que estavam ofertando pacotes ao Circuito da Fé.

Como procedimentos metodológicos para a pesquisa se fez uso das abordagens qualitativa e quantitativa, por meio de duas etapas, e distintos procedimentos para o tratamento dos dados coletados em cada uma delas. Para delinear o perfil e o comportamento dos turistas estabeleceu-se como amostra 100 turistas religiosos: a amplitude da amostra foi fundamentada na tabela de Arkin e Colton (1995) (Tables for Statisticians) para coeficiente de confiança de 95,5\%, em que a consulta de 100 indivíduos para uma demanda acima de 100.000 turistas é suficiente para obter um resultado com margem de erro máximo, para mais ou para menos, de 10 pontos

\footnotetext{
4 Disponível em:

<http://www.sebraesp.com.br/PortalSebraeSP/Vitrine/NegociosTuristicos/CircuitoReligioso/Documents/c ircuito_religioso_municipios.pdf $>$. Acesso em: 06/12/11.

${ }^{5}$ Disponível em:

<http://www.sebraesp.com.br/index.php/76-noticias/multissetorial/9283-visita-do-papa-trazoportunidades-ao-circuito-turistico-religioso. Acesso: 27/11/13.
} 
percentuais (pp) ${ }^{6}$. Os parâmetros estabelecidos foram: 1 - Formas de deslocamento; 2 Preparação; 3 - Motivação; 4 - Expectativas para a viagem; 5 - Relação tempo x visita nos atrativos; 6 - Relação com a comunidade local; 7 - Atividades nos atrativos; 8 Preferências por grupo ou de forma solitária; 9 - Escolha do meio de hospedagem.

Sobre a concepção de pacotes, foram entrevistados funcionários de seis (6) agências ou operadoras turísticas que realizavam viagens para as cidades do Circuito da Fé do Brasil, sendo este número obtido a partir da identificação daquelas empresas que ofereciam pacotes de viagem para, pelo menos, duas das três principais cidades $^{7}$ pertencentes ao Circuito da Fé.

A escolha das agências se deu via web e a coleta das informações desses empreendimentos turísticos aconteceu de maneira informal, na qual ao se passar por um turista/consumidor buscou-se saber os diversos elementos que compunham a programação das viagens.

Desse modo, a interpretação final dos dados se deu por meio de uma análise comparativa a partir das seguintes categorias de análise:

\begin{tabular}{|c|}
\hline ELEMENTOS DE COMPARAÇÃO \\
\hline Escolha da categoria dos hotéis e pousadas \\
\hline Preparação espiritual e reflexiva para a viagem \\
\hline Tempo destinado ao lazer \\
\hline Momentos sozinhos e em grupo \\
\hline Interação com a comunidade local \\
\hline Tempo para a visita nos lugares sagrados \\
\hline QUADRO 1 - ELEMENTOS DE COMPARAÇÃO \\
Fonte: Elaboração própria.
\end{tabular}

\section{A MOTIVAÇÃO DO TURISTA RELIGIOSO, SEUS DESEJOS, PREFERÊNCIAS E COMPORTAMENTO}

Maslow (1954, apud SERRANO, 2011) ${ }^{8}$ afirma que a motivação é a consequência dos estímulos que atuam com força sobre as pessoas, levando-as a agir.

\footnotetext{
6 Disponível em:

$<$ http://bibliotecadigital.fgv.br/dspace/bitstream/handle/10438/2590/127141.pdf?sequence=3>. Acesso em: $10 / 10 / 11$

7 As cidades de Lorena e Canas não foram contempladas nessa pesquisa por terem sido recentemente incorporadas ao Circuito.
}

${ }^{8}$ MASLOW, A. H. (1954). Motivation and personality. New York: Harper. 
Sendo assim, para que exista ação ou reação é essencial a existência de um dado estímulo decorrente de algo externo ou derivado do próprio organismo. Para o autor, as necessidades dos seres humanos correspondem a uma hierarquia, uma vez que, no momento em que o indivíduo atinge uma necessidade, passa a existir outra em seu lugar, necessitando sempre que as pessoas busquem meios para atendê-la.

Segundo Maslow (1954 apud SERRANO, 2011)9 , há cinco níveis a serem escalados pelos seres humanos. No topo, estão as necessidades mais elevadas, ou seja, autorrealização - e na base aquelas básicas - ou seja, fisiológicas ou básicas.

A motivação de um turista, é uma edificação inconsciente usada para diferenciar e conhecer novas forças que definem o comportamento humano com intensidade equivalente ao instinto, à necessidade e ao desejo que estimulam o homem a atuar e a viajar (BRITT $^{10} 1976$ apud BENI, 2001, p. 78). Complementando a ideia exposta acima, Chan (2011, p. 39) defende que é preciso diferenciar o significado do desejo do turista das necessidades do mesmo. O primeiro é definido como "a forma que adotam as necessidades a serem modeladas pela sociedade, pela cultura e pela própria personalidade de um homem". Quando uma sociedade se desenvolve, seus membros possuem um alcance de uma maior quantidade de elementos e em decorrência disso uma ampliação de seus desejos ou de suas expectativas, mas não de suas necessidades, que serão basicamente as mesmas de antes. (CHAN, 2011). Sendo assim, é possível dizer que uma necessidade passa a ser uma motivação quando sua intensidade faz com que a pessoa passe a buscar a sua satisfação.

Igualmente, em relação ao turismo religioso, pode-se dizer que ele, tem como motivação principal a fé, estando ligado intensamente ao calendário religioso da localidade receptora do fluxo turístico (TURISMO RELIGIOSO, 2010).

Se a motivação da fé é tida como o principal estímulo para o deslocamento do turista religioso, se faz necessário entender o que é a fé e quais são suas características. Focando na ótica da teologia, Libanio (2005, p. 68) explica que a fé em seu estado puro é uma escuta da Palavra Revelada. Segundo o autor só há fé onde há revelação divina.

Pensando nas características que a fé possui, Fracasso (1997, p. 33) afirma que ela é um ato racional de adesão e de aceitação, despido de toda emotividade. De acordo

\footnotetext{
${ }^{9}$ MASLOW, A. H. (1954). Motivation and personality. New York: Harper.

${ }^{10}$ BRITT, L. "Advertising psychology and research", Review of Tourism and Recreation, 1976.
} 
com o autor, a emoção é a vibração do sistema nervoso, podendo seguir os atos de fé sem fazer parte dela. Fracasso (1997) segue a mesma colocação de Libanio (2005, p. 32), em que a fé consiste em ter atitudes que refletem a palavra de Deus na vida e que é por ela que o indivíduo percebe o verdadeiro sentido dos acontecimentos que o cercam e que sucedem sua vida.

Portanto, sendo a fé uma manifestação racional do ser humano e que traduz a revelação divina nas atitudes tidas ao longo da vida, é possível dizer que o turista que se desloca a lugares sagrados tendo como motivação a fé, tem, por sua vez, o objetivo de estar mais próximo da revelação de Deus e de transformar-se e tornar-se um indivíduo melhor.

Outras motivações que estão também ligadas à fé podem ser percebidas, como a renovação espiritual e psicológica do indivíduo. Nessa ótica, Pellegrini (1997) define que as motivações principais do peregrino são a qualidade das experiências vivenciadas e um processo simbólico de regeneração psicológica e espiritual.

Entretanto, nem todo turista religioso tem como desejo principal a fé e os aspectos relacionados a ela, podendo ser a motivação voltada para a cultura, o lazer e o contato com a natureza. Nesse sentido, Oliveira (2006) coloca que no campo da religiosidade, existe uma permanente reconstrução de práticas e valores, no qual o turismo religioso compreende a realização de visitas que aproximem o indivíduo ao sagrado, mas que também, na lógica cultural da visitação e da comunicação, é capaz de compatibilizar, no mesmo meio, o peregrino ecoturista e o romeiro excursionista. Tal fato ocorre porque a prática do turista religioso, em uma localidade, é ampla e diferenciada.

Por meio de entrevistas com turistas religiosos buscou-se compreender o que motivava o seu deslocamento aos lugares sagrados inerentes a fé católica, observando seu perfil e as características da prática do turismo religioso por esse tipo de turista.

\subsection{INTERPRETANDO O COMPORTAMENTO DOS TURISTAS RELIGIOSOS}

Por meio das entrevistas realizadas, pôde-se perceber que a maioria dos turistas manifestou preferir viagens em grupos bem como em companhia de sua própria família. Foi observado que os turistas religiosos entrevistados ao longo dessa pesquisa não 
demonstraram ter o hábito de viajar por meio de agências de viagens, uma vez que apenas $6 \%$ dos turistas optaram por esse tipo de acompanhamento.

A respeito da preparação para a viagem constatou-se que a maioria dos turistas entrevistados mencionou ter o hábito de fazer algum tipo de preparação espiritual ou psicológica antes de viajar. Essa preparação foi feita na maioria das vezes, dentro do meio de transporte e aconteceram, principalmente, por meio de orações. Outras atividades também são realizadas, como a entoação de cânticos e reflexões que ajudam o turista a se preparar para as experiências futuras.

Em relação à motivação de um turista religioso, percebeu-se que a fé e todos os seus atributos consistiu no principal motivo para o deslocamento do mesmo aos lugares sagrados. Porém, outros desejos também foram citados demonstrando representatividade no que tange à sua motivação principal. Se forem somadas as respostas obtidas em relação aos itens que envolvem a cultura e o lazer, pode-se dizer que $30 \%$ dos turistas apontaram possuir como um dos desejos principais conhecer o local, suas histórias e tudo que envolve a cultura, e poder ao mesmo tempo realizar atividades relacionadas ao lazer nos atrativos e equipamentos turísticos que os proporcionassem.

Confirmando o resultado obtido em relação à motivação do turista religioso, a sua maior expectativa foi a de estar próximo de Deus, renovando a sua fé, sua espiritualidade e seu psicológico. Além disso, expectativas relacionadas com o conhecimento de lugares bonitos e com a diversão permaneceram presentes em $38 \%$ das respostas dos entrevistados. Importante ressaltar que o resultado obtido nessa variável foi inesperado, uma vez que se acreditava que as respostas relacionadas com a expectativa do turista religioso iriam envolver essencialmente as questões ligadas à fé.

A respeito da relação tempo e visitação foi observado que a maior parte dos turistas mencionou acreditar que o tempo deve ser limitado, mas amplo. Eles alegaram que para obter uma experiência mais concreta é desejosa uma disponibilidade maior de tempo para a realização de reflexões e de orações e para contemplação do lugar.

No tocante a relação com a comunidade local, a maior parte dos turistas entrevistados comentou possuir o hábito de interagir com a população, afirmando ser importante conhecer o local e suas histórias por meio dela, e, poder principalmente estabelecer novos vínculos de amizade. 
Em relação aos hábitos de visitação dos turistas religiosos nos atrativos, pôde-se perceber que eles foram bem variados. $\mathrm{Na}$ maior parte das vezes, eles realizaram orações e participaram das celebrações santas. Mas, em outros casos, muitos deles citaram ir para observar o local e conhecer a história. No entanto, há aqueles que comentaram procurar independente do atrativo realizar atividades que se relacionassem com o lazer.

A respeito da preferência dos turistas em ficar só ou em grupos, notou-se que a maior parte dos entrevistados mencionou gostar de ficar em grupo, mas um número considerável de turistas manifestou sentir a necessidade de se ausentar do grupo para alcançar um encontro mais intenso com Deus e realizar suas orações pessoais e reflexões.

Quanto às características dos meios de hospedagem, um número considerável de turistas optou por aquelas que oferecem conforto e que sejam ao mesmo tempo familiares, ou seja, que os deixe à vontade. Demonstrou-se relevante que um número expressivo de turistas também buscou pela acessibilidade. O luxo ou altos padrões de conforto não se estabeleceram entre os meios de hospedagem mais escolhidos pelos turistas religiosos.

Desse modo, o comportamento da maior parte dos turistas religiosos entrevistados pode ser sintetizado da seguinte maneira:

\section{O COMPORTAMENTO DO TURISTA RELIGIOSO}

Viaja aos lugares sagrados acompanhado da família ou em excursões organizadas

Sua motivação principal é a fé, a religiosidade, a renovação psicológica e espiritual acompanhada pelo desejo de conhecer lugares bonitos e realizar atividades de lazer Realiza uma preparação espiritual e psicológica antes da viagem

O tempo para as visitas deve ser limitado, mas com uma extensão considerável Busca interagir com a comunidade local

Nos atrativos possui o hábito de rezar, observar o local e saber das suas histórias Tem a preferência por grupo, mas possui a necessidade de ficar sozinho em alguns momentos Prefere meios de hospedagem confortáveis e familiares

QUADRO 2 - O COMPORTAMENTO DO TURISTA RELIGIOSO

Fonte: Dados da pesquisa.

\subsection{PEREGRINOS, ROMEIROS, ROMEIROS-TURISTAS OU PEREGRINOS- ROMEIROS?}

Pellegrini (1997) relata que toda viagem é uma atitude sagrada, e todo viajante é um herói inquieto. Para ele a busca pelo self, acaba sendo uma busca por uma conexão 
com alguma forma de divindade. Por isso desde o início dos tempos ocorriam diversas epopeias religiosas e espirituais ligadas à ideia de viagem, sendo possível notar que viagens motivadas pela fé sempre estiveram presentes na história da humanidade e isso pode ser percebido na atualidade.

De acordo com Novaes ${ }^{11}$ (2000, p. 129 apud SILVA, 2004) o turismo religioso, após o turismo de férias e de negócios, é o que mais cresce no mundo. Isso ocorre porque, segundo a autora, além dos aspectos místicos e dogmáticos, as religiões adotam o papel de agentes culturais pelas manifestações de proteção a valores antigos, de intervenção na sociedade atual e na vigilância no que se diz respeito ao futuro dos indivíduos e das sociedades Em uma análise mais conceitual, Andrade (2000) define o turismo religioso como algo que está ligado a experiência dos indivíduos em relação à fé, à caridade e à esperança e que ocorre a partir de visitas a determinados lugares onde o místico esteja presente.

O Ministério do Turismo (Brasil, 2010 p. 19) apresentou na $3^{\circ}$ edição da obra: "Turismo Cultural: Orientações Básicas" a definição do turismo religioso, que está relacionada às atividades turísticas inerentes a uma busca espiritual e a prática religiosa em ambientes e eventos ligados às religiões institucionalizadas, independentemente da crença.

É necessário também compreender as diferenças entre as tipologias existentes relacionadas aos indivíduos que praticam o turismo religioso. É possível começar pelo peregrino que segundo Ribeiro $(2003$, p. 1) é aquele que se percebe como alguém que está em busca de Deus, a procura de respostas e de auxílio para as suas necessidades espirituais ou materiais.

Nessa mesma perspectiva Dias (2003b, p. 22 b) também disserta sobre a tipologia peregrino que é também denominada por ele de romeiro. Para o autor, as atitudes do peregrino estão associadas à experiência individual vivenciada pelo indivíduo que faz a jornada, uma motivação inerente à sua espiritualidade, a uma busca por um aperfeiçoamento, pelo cumprimento de votos ou mesmo a uma participação em uma festa religiosa importante, entre outros fatores. A peregrinação é na maioria das vezes realizada individualmente o que não exclui o caráter coletivo que ela muitas vezes assumiu.

${ }^{11}$ NOVAES, M. H. Turismo religioso. In: ANSARAH, M. G. dos R. Turismo: segmentação de mercado. 3. ed. São Paulo: Futura, 2000. 
Para Palma (2009), a diferença entre romeiros e peregrinos vai muito além do número de pessoas que realizam a viagem, estando relacionada principalmente com a motivação para a viagem. Para ele, enquanto os peregrinos realizam suas jornadas movidos pela fé, um número relevante de romeiros faz a romaria com a finalidade de pagar uma promessa, em função de graça ou uma benção alcançada. Para Palma (2009) os romeiros caminham de forma rápida querendo chegar rápido ao destino enquanto os peregrinos caminham de forma contemplativa, sem pressa para concluir sua jornada. Para o autor os romeiros possuem a preferência em caminhar em grupos enquanto os peregrinos preferem a solidão.

Ao longo do tempo a peregrinação e a romaria passaram por transformações importantes e que continuam a ocorrer nos dias atuais revelando o seu caráter dinâmico. Ribeiro (2003, p. 1) resgata essas mudanças e apresenta que na antiguidade, essas manifestações de fé possuíam um caráter de ritual, de oração e de busca pelo sagrado em lugares denominados santos. Durante a idade média, a motivação para a peregrinação estava mais relacionada a estratégias políticas e de devoção, nas quais as penitências e a fé coexistiram com os perigos e a necessidade de ocupar regiões, protegendo-as de invasores (RIBEIRO, 2003).

Em meados do século XIX, as peregrinações e as romarias passaram a dividir não apenas a fé, como também o desejo de usufruir de momentos de lazer em conjunto, sendo, os meios de deslocamento, acomodação e alimentação, planejados em paralelos às atividades religiosas (RIBEIRO, 2003).

$\mathrm{Na}$ atualidade, as características apresentadas por Ribeiro (2003) têm mantido sua configuração, uma vez que as romarias e peregrinações continuam a ser, de modo geral, uma oportunidade de assegurar a integração de um grupo, e, assim são vividas, ao mesmo tempo, como cerimônia religiosa e como lazer. Esse mesmo autor defende que a relação entre o antigo e o novo provocou novas denotações, onde as peregrinações evoluíram para formas de lazer, nas quais a recreação e o divertimento tendem a colocar-se acima da espiritualidade.

Outra tipologia presente no turismo religioso é denominada "romeiros-turistas" que segundo Steil (2003) se diferenciam dos romeiros tradicionais não apenas por sua ideologia religiosa, mas principalmente pelas estruturas de significados dentro das quais inserem sua experiência. Para essa nova categoria de romeiros, a romaria em si se torna 
uma curiosidade ou um aspecto peculiar a ser observado. Para eles, o importante é se colocar como um observador externo, no atributo de turista, frente a uma experiência vivenciada por outros e que se torna elemento de admiração. Steil (2003)

Para analisar o comportamento do turista religioso, buscou-se classificá-los em "peregrinos", "romeiros" e "romeiros-turista". Aqueles que não se enquadraram em nenhuma dessas tipologias, foram então classificados numa nova tipologia denominada "peregrinos-romeiros". Essa nova tipologia foi criada após observar que atualmente há uma mescla entre as características dos peregrinos e as dos romeiros e que os elementos incorporados podem ser colocados em uma zona de transição entre as duas primeiras tipologias citadas, e ainda incorporar outros elementos presentes no contexto atual.

Desse modo, seguem abaixo os atributos escolhidos para classificação dos turistas entrevistados:

\begin{tabular}{|c|c|c|c|c|}
\hline CRITÉRIOS & Romeiros & Peregrinos & $\begin{array}{l}\text { Romeiros- } \\
\text { Turistas }\end{array}$ & $\begin{array}{l}\text { Peregrinos- } \\
\text { Romeiros }\end{array}$ \\
\hline \multirow{5}{*}{ Motivação } & \multirow{2}{*}{$\begin{array}{l}\text { Pagar uma promessa } \\
\text { por graça obtida. }\end{array}$} & Fé & \multirow{5}{*}{$\begin{array}{l}\text { Curiosidade em } \\
\text { relação à } \\
\text { manifestação de fé } \\
\text { e às festividades }\end{array}$} & Pagar promessa \\
\hline & & \multirow{2}{*}{$\begin{array}{l}\text { Renovação } \\
\text { psicológica }\end{array}$} & & Fé \\
\hline & \multirow{3}{*}{$\begin{array}{l}\text { Busca festividades } \\
\text { ligadas aos santos, } \\
\text { milagres e afins. }\end{array}$} & & & $\begin{array}{l}\text { Renovação } \\
\text { psicológica }\end{array}$ \\
\hline & & \multirow{2}{*}{ Encontro com Deus } & & Encontro com Deus \\
\hline & & & & Lazer e cultura \\
\hline $\begin{array}{c}\text { Atitudes no } \\
\text { Deslocamento }\end{array}$ & $\begin{array}{c}\text { Acesso rápido ao } \\
\text { destino }\end{array}$ & $\begin{array}{c}\text { Contemplar o } \\
\text { caminho de acesso } \\
\text { ao destino. }\end{array}$ & $\begin{array}{c}\text { Acesso rápido ao } \\
\text { destino }\end{array}$ & $\begin{array}{l}\text { Para alguns a } \\
\text { contemplação do } \\
\text { deslocamento } \\
\text { necessária } \\
\text { enquanto para } \\
\text { outros o acesso } \\
\text { rápido ao destino é } \\
\text { a prioridade. }\end{array}$ \\
\hline Companhia & Preferem grupos & $\begin{array}{c}\text { Preferem estar } \\
\text { sozinhos }\end{array}$ & $\begin{array}{c}\text { Em grupos ou } \\
\text { sozinhos }\end{array}$ & $\begin{array}{l}\text { Em grupos e } \\
\text { sozinhos }\end{array}$ \\
\hline
\end{tabular}

QUADRO 3 - CRITÉRIOS DE CLASSIFICAÇÃO

Fonte: Elaborado a partir da classificação de PALMA (2009), DIAS (2003 a) e STEIL (2003).

No gráfico a seguir é possível observar a distribuição dos mesmos segundo as características expostas no quadro anterior. 


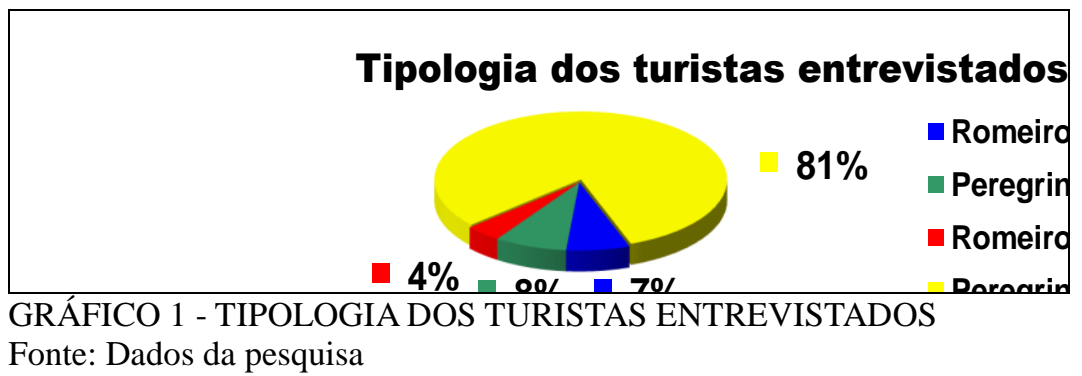

Como se pode perceber, um expressivo número de turistas situou-se numa faixa de transição entre os "peregrinos" e os "romeiros", no qual foram denominados "peregrinos-romeiros" e contabilizaram $81 \%$ dos entrevistados. Como foi apresentado por Ribeiro (2003, p. 2), no contexto atual as peregrinações e as romarias se apresentam com uma oportunidade de certificar a existência e a relação de um grupo, compartilhando, simultaneamente, o religioso, o lazer e a cultura.

Um dos motivos para que essa mescla tenha ocorrido pode ter advindo da falta de tempo dos indivíduos na atualidade, de forma que a busca por Deus e pela renovação espiritual também pode ser obtida concomitantemente a uma vivência de lazer. Ressaltase que esse tipo de turista comentou ser importante ter alguns momentos de solitude para realizar suas orações e reflexões, mas que a presença e a companhia de um grupo são essenciais durante uma viagem.

\section{A EXPERIÊNCIA E A COMERCIALIZAÇÃO NA CONCEPÇÃO DOS PACOTES TURÍSTICOS}

Recentemente, a experiência vem sendo analisada e colocada como um diferencial em diversos segmentos do mercado, inclusive o turístico. Ela começou a ser valorizada como um contrapeso ao movimento massificado que surgiu a partir de 1945 , após o término da Segunda Guerra Mundial em que fatores ligados à modernização e formas de deslocamento dos viajantes, aos investimentos em infraestrutura, ao aparecimento dos operadores turísticos, às férias remuneradas oferecidas à classe trabalhadora entre outros fatores possibilitando que a grande maioria das classes sociais - de países industrializados - agregasse o turismo em suas atividades. (DIAS, 2003a). 
Em contrapartida a esse movimento massificado, em 1999 surgiu o conceito de "Economia da Experiência" originado a partir da obra do dinamarquês Rolf Jensen intitulada "A sociedade dos sonhos"12. O trabalho de James Gilmore e Joseph Pine (2008), intitulado "Economia da Experiência", foi sendo assimilado pelo turismo, propagando novos valores ao mercado. O conceito traz como base a "inovação" tendo como finalidade agregar valor à oferta turística e gerar maior qualidade aos destinos. Ela vem sendo incorporada por aqueles que desejam inovar os processos de comercialização e formatação de produtos, tendo a promoção e a venda de experiências únicas como um fator diferencial para sua comercialização (BRASIL, 2010, p. 25-26).

Com o início das mudanças de um turismo massificado para um que ofereça experiências aos turistas, os serviços e produtos já não conseguem atender as expectativas dos consumidores, uma vez que estes vêm desejando obter verdadeiras experiências. Entretanto, diante da espetacularização que ronda muitas experiências, os consumidores vêm buscando ofertas que visem o real, o original e o autêntico. Os indivíduos desejam pagar não somente por experiências de alta tecnologia, e sim também por experiências de alto envolvimento (GILMORE; PINE, 2008).

Assim, a "Economia de Experiência" pode trazer à atividade turística uma singularidade e um diferencial que leva em consideração a vivência que o turista terá na localidade. Para o turismo religioso isso se constitui como um fator fundamental, uma vez que o que move esse tipo de turista é, em grande parte, o desejo de experienciar a espiritualidade e a fé intrínseca no destino. Para que tal motivação possa ser plenamente satisfatória é necessário que o indivíduo tenha a liberdade de criar as experiências que deseja vivenciar durante a sua viagem.

Pensando na ótica em que se insere o turismo religioso é possível dizer que ele está relacionado ao turismo cultural ${ }^{13}$ e este por sua vez está inserido dentro do chamado

\footnotetext{
12 JENSEN, R. The Dream Society: How the Coming Shift from Information to Imagination Will Transform Your Business: Nova York: MacGrow-Hill, 1999.

13 O Turismo Religioso faz parte do turismo cultural onde o turista obtém novos conhecimentos através de manifestações religiosas, arquitetura de igrejas e museus sacros. É um tipo de segmento turístico que envolve um grande movimento de pessoas, que se deslocam de seu local de origem motivados pela fé [...]. (PORTAL TURISMO RELIGIOSO, 2012). Disponível em: <Turismo Religioso. http://www.turismoreligioso.org.br/?system=news\&action=read\&id=219 >. Acesso em: 06/12/12.
} 
turismo alternativo (MIECZOWSI ${ }^{14}$, 1995 apud WERING; NEIL, 2001, p. 5). O turismo alternativo surge dentro da perspectiva que visa minimizar os efeitos negativos do turismo de massa procurando formas alternativas ao turismo global. Desse modo, esse segmento procura agir diferentemente, buscando lugares inexplorados, realizando atividades fora do comum, procurando maior contato com a comunidade e vivenciando de forma mais intensa o local (KRIPPENDORF ${ }^{15}, 1989$ apud GOMES, 2000).

Desse modo, dentro do turismo alternativo é possível encontrar fundamentos da "Economia da experiência" como, a busca por uma vivência mais intensa com a comunidade e com o destino e a própria proposta de uma atitude diferenciada do turista de massa, pautada na sustentabilidade em seus âmbitos primordiais - social, econômico, ecológico, espacial e cultural.

Além da forte ligação estabelecida entre o turismo religioso com o turismo cultural, há também discussões a respeito da sua inserção dentro do turismo de lazer. O lazer é tido como uma vivência de atividades culturais, considerando tempo/espaço disponíveis e uma postura assumida pelos indivíduos neste tipo de experiência, marcadas por uma sensação de liberdade, motivada pela busca da satisfação e pelo desfrute da ocasião vivida (GOMES; PINTO, 2009, p. 68). Assim, a liberdade de opção baseia-se numa real ocupação do tempo de lazer, e como consequência, o indivíduo que escolher preencher o seu tempo livre com a religião estará realizando uma vivência de lazer (RIBEIRO, 2010, p. 11).

Retomando a conceituação dos termos aqui propostos, a comercialização segundo o dicionário online Michaelis (2012) ${ }^{16}$ é denominada, como: "2 Subordinação de atividades, anteriormente alheias à esfera econômica, ao princípio da troca monetária determinada pelo desejo de lucro". Essa definição expressa o cunho mercadológico que a comercialização envolve, tendo o lucro como seu objetivo final. Finalmente, a palavra

\footnotetext{
${ }^{14}$ MIECZOWSI, Z. Environmental issues of tourism and recreation. University Press of America, Inc: Lantarn, Maryland. (1995).

${ }^{15}$ KRIPPENDORF, J. Sociologia do Turismo: para uma nova compreensão do lazer e das viagens. Rio de Janeiro: Civilização Brasileira, 1989, 236 p.

${ }^{16}$ Disponível em: <http://michaelis.uol.com.br/moderno/portugues/index.php?lingua=portuguesportugues\&palavra=região>. (Português Brasil). Acesso em: 02/01/2012.
} 
concepção, pode ser definida segundo o dicionário online Michaelis (2012) ${ }^{17}$, como: "2 Geração [...] 5 Criação [...]." Diante desse conceito, a concepção é algo que é criado e que está na origem de algo, sendo portanto o seu fundamento e a sua base.

Tendo em vista as definições apresentadas, torna-se necessário compreender algumas diferenças existentes entre as empresas definidas por Molina (2003) como "industriais" e "pós-industriais". As "empresas industriais" são aquelas que surgiram a partir de 1950, tendo como foco o turismo de sol e praia. Elas se baseiam nas possibilidades oferecidas pelo capital financeiro, deixando para um segundo plano o capital humano, as ideias e a visão do futuro (MOLINA, 2003, p. 24-25).

Já as empresas “pós-industriais” são aquelas que nasceram em meados da década de 1980, constituindo parte de um paradigma que despreza os valores, as metodologias e as técnicas denominadas 'tradicionais', que formam as bases do modelo das 'empresas industriais' (MOLINA, 2003, p. 26).

Diante dessas definições, é possível perceber que as empresas apresentadas possuem concepções distintas em relação à formatação de seus pacotes turísticos. Enquanto as "industriais" conduzem suas atividades pautadas no consumo e na coerção $^{18}$, as "pós-industriais" se concentram na qualidade do serviço, na motivação do turista e na concretização das experiências dos mesmos (MOLINA, 2003).

MOLINA (2003, p. 65) apresenta um esquema que exemplifica a concepção dos pacotes das empresas "industriais (vide esquema 1) e das empresas "pós-industriais" (vide esquema 2), demonstrando a ordem de prioridade dada pelas mesmas.

\section{PRODUTO - SERVICO - EXPERIÊNCIA DOS CLIENTES}

ESQUEMA 1 - CONCEPÇÃO DOS PACOTES TURÍSTICOS DAS “EMPRESAS INDUSTRIAIS" É Fonte: MOLINA (2003, p. 65).

\section{EXPERIÊNCIA DOS CLIENTES - SERVICO - PRODUTO}

ESQUEMA 2 - CONCEPÇÃO DOS PACOTES TURÍSTICOS DAS "EMPRESAS PÓSINDUSTRIAIS"

Fonte: MOLINA (2003, p. 65).

\footnotetext{
${ }^{17}$ Disponível em:

<http://michaelis.uol.com.br/moderno/portugues/index.php?lingua=portuguesportugues\&palavra=região>. (Português Brasil). Acesso em: 02/01/2012.
}

18 A palavra coerção refere-se, no sentido empregado, a limitação e restrição dos direitos segundo o Dicionário do Ministério da Educação (1986, p. 271). Nesse sentido supõe-se que Molina (2003) desejou expressar que as motivações do turista não são levadas em consideração para a formatação dos pacotes turísticos. 
É pertinente observar também as vantagens e as desvantagens dessas duas concepções, uma vez que a problemática dessa pesquisa visou descobrir se os empreendimentos que ofereciam pacotes para o Circuito da Fé no Brasil concebiam seus pacotes pautados na experiência ou na comercialização dos mesmos.

Desse modo, após uma pesquisa sobre ambos os temas, foram agrupadas as vantagens e desvantagens da comercialização e da experiência na concepção dos pacotes turísticos:

\begin{tabular}{|c|c|c|c|}
\hline \multicolumn{2}{|l|}{ EXPERIÊNCIA } & \multicolumn{2}{|c|}{ COMERCIALIZAÇÃO } \\
\hline Vantagens & Desvantagens & Vantagens & Desvantagens \\
\hline $\begin{array}{l}\text { *Maior relevância para os } \\
\text { componentes emocionais onde os } \\
\text { valores e os sentimentos adquirem } \\
\text { maior relevância que o componente } \\
\text { racional; } \\
\text { *Participação ativa do turista e maior } \\
\text { envolvimento da comunidade local; } \\
\text { * Inovação e diferencial competitivo; } \\
\text { *Agregação de valor ao produto; } \\
\text { *Consolidação do arranjo produtivo } \\
\text { dos pequenos negócios; } \\
\text { *Potencialização da oferta turística da } \\
\text { região; } \\
\text { * "Humanização da demanda"; } \\
\text { *Personalização e Diversificação; } \\
\text { *Habilidade de compreender o } \\
\text { ambiente e os turistas; }\end{array}$ & $\begin{array}{lr}\text { *Ocorrência } & \text { da } \\
\text { espetacularização } & \text { em } \\
\text { alguns casos; } & \\
\text { *Criação } & \text { de } \\
\text { estereótipos; } & \\
\text { *Aculturação } & \end{array}$ & $\begin{array}{ll}\text { *Maximização } & \\
\text { dos lucros; } & \\
\text { *Concentração de } & \text { na } \\
\text { esforços } & \text { na } \\
\text { promoção e } & \text { na } \\
\text { venda } & \end{array}$ & $\begin{array}{lr}\text { *Tendência à } & \text { à } \\
\text { promoção de } & \\
\text { viagens com o } \\
\text { intuito apenas } \\
\text { de fuga do } \\
\text { cotidiano; } \\
\text { *Tendência à } \\
\text { acomodação; } \\
\text { *Uniformização } \\
\text { da oferta } \\
\text { turística; } \\
\text { *Tendência à } \\
\text { qualidade } \\
\text { mínima }\end{array}$ \\
\hline
\end{tabular}

QUADRO 4 - VANTAGENS E DESVANTAGENS DA EXPERIÊNCIA E DA COMERCIALIZAÇÃO Fonte: Adaptado de BRASIL (2010); GILMORE e PINE (2008); KRIPPENDORF (2000); BRASIL e SEBRAE (2006); MOLINA (2003); PÉREZ (2009).

É importante ressaltar que para algumas características apresentadas a predominância de uma concepção não impede a existência da outra na formatação do pacote turístico. Ao contrário disso, os pacotes podem mesclar os elementos positivos de ambas as concepções, de forma a gerar um equilíbrio na origem dos mesmos.

Outro aspecto importante a ser salientado incide sobre a mudança do comportamento do consumidor que vem alterando suas prioridades e desejos, buscando ao invés de novos produtos e serviços, novas experiências (MOLINA, 2003). Desse modo, algumas empresas atualmente vêm reconhecendo a importância de atender cada cliente em sua singularidade e que a vivência e a experiência proporcionadas nos pacotes consistem em um fator diferencial e competitivo. 
Assim, com o desejo de conhecer qual era a concepção dos pacotes de empreendimentos que estavam promovendo viagens ao Circuito da fé foram mapeadas agências dos estados do Rio Grande do Sul, São Paulo, Espírito Santo, Minas Gerais, Bahia e Pernambuco contabilizando um total de 6. As agências analisadas tiveram o seguinte perfil: Sem uma segmentação específica: possuíam vários nichos de mercado inclusive o religioso e realizavam viagens para pelo menos duas cidades do Circuito da Fé no Brasil.

\subsection{A PROGRAMAÇÃO DOS PACOTES DE VIAGEM E O DESLOCAMENTO DOS TURISTAS AO CIRCUITO DA FÉ DO BRASIL}

Os roteiros criados pelos promotores das agências foram analisados com intuito de perceber sua flexibilidade. Desse modo, constatou-se que em três das seis agências os roteiros possuíam a programação fixa, ou seja, o grupo não tinha a autonomia para poder criar as experiências que ele desejasse vivenciar.

Constatou-se ainda, que em duas agências a programação era parcialmente personalizada. Uma delas com um roteiro fixo, sendo, entretanto disponibilizado um dia inteiro para que o turista pudesse usufruí-lo da maneira que ele desejasse. Além disso, os funcionários dessa mesma agência permitiam que o turista escolhesse a hospedagem que lhe fosse mais apropriada. Já na outra agência elaboravam o roteiro segundo as motivações do turista, porém o meio de hospedagem era determinado por ela. Apenas em uma agência se verificou a existência de um serviço totalmente personalizado, em que a programação era feita segundo as experiências que o turista desejasse ter e a escolha do meio de hospedagem também levava em conta as suas necessidades.

Em relação ao deslocamento dos turistas, buscou-se observar a permissão para realização de orações, reflexões e entoação de cânticos ao longo do deslocamento. Das falas dos entrevistados nas seis agências pesquisadas, verificou-se que em quatro se dava abertura para tal atitude e que apenas o entrevistado de uma se mostrou fechado para a realização das atividades explicitadas. Uma agência não foi contabilizada por não se obter informações necessárias dos seus funcionários. 


\subsection{OS RESULTADOS OBTIDOS EM RELAÇÃO ÀS CARACTERÍSTICAS DOS PACOTES OFERTADOS PELAS AGÊNCIAS PESQUISADAS}

Analisaram-se ainda as características das hospedagens escolhidas pelos gestores das agências, observou-se também se os mesmos disponibilizavam tempo na programação para que o turista pudesse desfrutar de momentos de lazer ou se a própria programação incluía atividades interativas. Analisou-se ainda, se a partir da agência ofereciam o serviço de guia de turismo em seus pacotes. Observou-se também o oferecimento de momentos particulares, em grupos e com a comunidade local e o tempo destinado às visitas nos atrativos. Assim, no quadro a seguir é possível visualizar o resultado encontrado.

\begin{tabular}{|c|c|}
\hline Características das hospedagens & Número de agências \\
\hline $\begin{array}{l}\text { Simples, com serviços básicos e que permitiam um número maior de } \\
\text { hóspedes, mas que apresentavam um bom grau de conforto. }\end{array}$ & 3 \\
\hline Luxuoso, com maior padrão de conforto. & 1 \\
\hline A escolha das características da hospedagem ficava a critério do turista. & 2 \\
\hline Momentos de lazer & Número de agências \\
\hline Momentos amplos de lazer. & 5 \\
\hline Momentos curtos destinados ao lazer. & 1 \\
\hline $\begin{array}{l}\text { Guia de turismo } \\
\end{array}$ & Número de agências \\
\hline Disponibilizavam. & 5 \\
\hline Não disponibilizavam. & 1 \\
\hline Os momentos sozinhos, em grupos e com a comunidade local & Número de agências \\
\hline Proporcionavam esses momentos. & 2 \\
\hline Não proporcionavam esses momentos. & 4 \\
\hline Tempo para visita & Número de agências \\
\hline Estabeleciam limites para as visitas. & 4 \\
\hline Programavam o tempo da visita segundo a necessidade do turista. & 2 \\
\hline $\begin{array}{l}\text { Quadro } 5-\text { AS CARACTERÍSTICAS DOS } \\
\text { PESQUISADAS. } \\
\text { Fonte: dados da pesquisa, } 2012 .\end{array}$ & OS PELAS AGEN \\
\hline
\end{tabular}

\subsection{A CONCEPÇÃO DOS PACOTES DAS AGÊNCIAS ANALISADAS}

Tendo como base os depoimentos dos entrevistados sobre a apresentação das características dos pacotes das agências delimitadas e o diagnóstico apresentado anteriormente, pode-se dizer que as agências, com exceção de uma, se encontravam em uma fase de transição - de uma concepção de pacotes que visava apenas à a comercialização para outra que visava proporcionar experiências aos turistas. 
Apenas uma agência estava oferecendo serviços totalmente personalizados, desde a programação até a escolha do meio de hospedagem. Ela visava um atendimento diferenciado tentando atender cada turista segundo as suas necessidades e expectativas. Foi observado que a maioria das agências oferecia liberdade ao turista no que tange à preparação para a viagem dentro do meio de locomoção.

Notou-se também que a maior parte dos roteiros disponibilizava tempo destinado ao lazer. Alguns entrevistados das agências demonstraram ter maior consciência da importância que é conceder ao turista o desfrute de outras experiências para além das oferecidas pelo pacote. Em relação ao comentado pelos entrevistados sobre a parte cultural constatou-se que a maioria das agências oferecia o serviço de guia de turismo. Esse serviço foi considerado importante pelos mesmos, por entenderem que o turismo religioso tem um forte apelo cultural.

Em relação ao resultado obtido junto aos entrevistados quanto aos meios de hospedagem, verificou-se que a maior parte dos entrevistados das agências estava optando por oferecer hospedagens simples e confortáveis, pelos mesmos perceberem que a motivação principal de um turista religioso é a fé. Entretanto, com as tendências de um turismo religioso voltado também para o lazer, se faz necessário uma maior abertura dos gestores das agências para esse tipo de experiência que também pode ser vivenciada dentro de um meio de hospedagem.

No que tange à liberdade para ficar só e a interação com a comunidade local, a partir dos entrevistados, constatou-se que poucas agências possibilitavam em seus pacotes desfrutar tais momentos, mantendo uma programação estruturada, na maior parte do tempo, com o grupo organizado por ela.

Em relação ao tempo destinado às visitas, pode-se dizer que foram identificados aspectos de uma concepção voltada para comercialização, em que o foco não é a experiência que se pode ter em um lugar, mas sim o fato de conhecê-lo de forma rápida e poder levar como lembrança fotos do mesmo. Tal fato pode ser notado no diagnóstico em que os promotores da maioria das agências programavam diversas atividades dentro de um mesmo dia com horários determinados. Essa atitude muitas vezes não permite que o turista realize grande parte dos seus desejos comprometendo a experiência do mesmo. 
Desse modo, pode-se dizer que nos pacotes turísticos elaborados pelas agências e operadoras turísticas com destino ao Circuito da Fé, se começava a considerar algumas características importantes ligadas aos fatores relacionados com a experiência. $\mathrm{Na}$ concepção desses pacotes se estava abarcando uma fase de transição nos quais alguns aspectos ligados à comercialização como o tempo destinado as visitas e a liberdade em ficar só e interagir com a comunidade local, ainda estavam comprometendo uma concepção voltada para uma vivência mais intensa da fé na localidade. Sendo assim, os pacotes não estavam sendo concebidos totalmente pelo viés da experiência que os clientes desejavam ter, por outro lado importantes elementos desta vinham sendo considerados no momento de formatá-los.

\subsection{A EXPERIÊNCIA DESEJADA PELOS TURISTAS E OS SERVIÇOS OFERECIDOS PELAS AGÊNCIAS MAPEADAS}

Com o objetivo de analisar se a experiência desejada pelos turistas estava sendo contemplada na oferta dos pacotes disponibilizados pelas agências mapeadas, criou-se um quadro (vide quadro 6) com a finalidade de comparar mais precisamente as variáveis.

\section{A EXPERIÊNCIA DESEJADA PELOS OS SERVIÇOS OFERECIDOS PELAS AGÊNCIAS} TURISTAS

Renovar a fé, vivenciar a Constatou-se que os entrevistados das agências, de um modo religiosidade, se renovar psicológica geral, demonstraram estar se adaptando, tentando oferecer e espiritualmente, desfrutar de serviços que atinjam as expectativas particulares do turista. momentos de lazer e conhecer Porém, ainda há uma grande inflexibilidade na programação dos lugares bonitos. pacotes, que comprometem muitas vezes uma experiência mais profunda da fé. Quanto ao lazer, verificou-se que a maioria das agências busca incorporá-lo de algum modo nos roteiros.

Realizar uma preparação espiritual e Liberdade para realizar uma preparação espiritual e psicológica ao psicológica antes da viagem. longo do deslocamento

Ter um tempo mais amplo para A grande maioria dos entrevistados mencionou que desfrutar e experienciar os atrativos. $\quad$ disponibilizavam um curto tempo para as visitas nos atrativos

Ter a liberdade de interagir com a A maior parte dos entrevistados ainda não estava oferecendo uma comunidade local e ficar sozinho nos vasta liberdade para a interação com a comunidade local e para o momentos em que isso se fizesse desfrute de momentos sozinho.

necessário.

Poder conhecer as histórias, as A maior parte dos entrevistados mencionou oferecer serviço de crenças e a cultura do local. guia por entender que os aspectos culturais são fundamentais dentro do turismo religioso

Poder desfrutar de um mínimo de conforto no meio de hospedagem e se A maior parte dos entrevistados das agências mencionou que sentir a vontade no mesmo. ofereciam em seus pacotes, hospedagens confortáveis e familiares.

QUADRO 6 - A EXPERIÊNCIA DESEJADA PELOS TURISTAS E OS SERVIÇOS OFERECIDOS PELAS AGÊNCIAS.

Fonte: dados da pesquisa, 2012. 


\section{CONSIDERAÇÕES FINAIS}

Como exposto, verificou-se a ocorrência de profissionais de algumas agências que programavam seus pacotes motivados na fé e em um serviço personalizado ao turista visando, dessa forma, garantir que as suas expectativas e motivações, fossem pautadas somente na fé ou em outros aspectos demandados por eles. Entretanto, em algumas agências foi notado que, pelo fato delas se situarem em uma fase de transição entre uma concepção pautada na comercialização e outra voltada para a experiência - a vivência da fé, se encontrava, muitas vezes, comprometida devido à falta da flexibilidade em alguns elementos encontrados nos pacotes.

É possível afirmar que os pacotes não estavam sendo concebidos totalmente sob o viés econômico, sendo considerados alguns aspectos importantes relacionados com a experiência da fé e outras motivações desejadas pelos turistas. Ressalta-se que a fase de transição a qual as agências estavam passando demandam tempo e um esforço para ao mesmo tempo poder satisfazer o cliente atendendo-o de forma inovadora e, assim, diferenciada e garantir a vitalidade da empresa.

Nesse sentido, foi possível observar que o comportamento do turista religioso estava voltado para uma motivação pautada na espiritualidade, mas fortemente acompanhado pela cultura e pelo desfrute do lazer nas localidades que apresentavam potencialidades sagradas. Salientou-se que a tríade encontrada - fé, cultura e lazer configurou-se como uma grande descoberta nos resultados da pesquisa, uma vez que imaginou-se que a fé estaria presente em praticamente todas as respostas dos turistas e que o lazer e a cultura apareceriam apenas em algumas respostas esporádicas.

Em outra perspectiva, é importante destacar que a pesquisa foi estruturada a partir de três eixos: a percepção dos turistas, a relação desses com as agências de viagens e a estruturação de pacotes turísticos pelas empresas pesquisadas. Contudo, embora o estudo tenha delineado um perfil sobre a estruturação e comercialização de pacotes cuja motivação principal reside no turismo religioso, um dado revelado e significativo, identificou que a maioria dos turistas não fizeram ou não fazem uso dos serviços prestados pelas agências de turismo ao realizar suas viagens. Por essa razão, essa fase de transição encontrada pode ser um indício de apenas um ajuste mediante a competição do setor, e não efetivamente pela assimilação e reconhecimento da 
necessidade de estruturar os pacotes pensando em que tipo de experiência pode ser revelada ao longo de uma viagem, e desconsiderando a experiência como um elo de composição inovador dos produtos ofertados.

Acredita-se que esse trabalho ofereça como contribuição um estudo para as agências e operadoras turísticas que lidam diretamente com o turista religioso, uma vez que a partir do conhecimento do comportamento desse público, elas possam adaptar seus pacotes oferecendo serviços cada vez mais personalizados e adequados a essa nova tendência.

Sugere-se a continuação da análise dos pacotes turísticos de outras agências que oferecem como destino o Circuito da Fé do Brasil, e que turistas que utilizaram desses pacotes sejam entrevistados com intuito de buscar aprofundar se suas motivações estão sendo levadas em consideração na formatação dos mesmos.

\section{REFERÊNCIAS}

ANDRADE, J. V. Turismo fundamentos e dimensões. São Paulo: Ática, 2000.

BENI, M. C. Análise Estrutural do Turismo. 6. ed. São Paulo: Editora SENAC São Paulo, 2001.

BRASIL, Ministério do Turismo. Turismo Cultural: Orientações Básicas. 3. ed. Brasília, 2010.

BRASIL, Ministério do Turismo; SEBRAE. Tour da Experiência. 2006. Disponível em:

$<$ http://www.turismo.gov.br/export/sites/default/turismo/o_ministerio/publicacoes/down loads_publicacoes/Estudo_de_Caso_Tour_Experiencia.pdf>. Acesso em: 06/12/2011.

CHAN, N. Circuitos Turísticos: Programacion y Cotatizacion. Argentina: Copyright Ediciones Turísticas, 2001.

CURY, A. Turismo religioso estimula economia de mais de 300 cidades do país. Disponível em: http://g1.globo.com/economia-e-negocios/noticia/2010/09/turismo-religioso-estimula-economia-demais-de-300-cidades-do-pais.html. Acesso em: 05/12/2011

DIAS, Reinaldo. Sociologia do turismo. São Paulo: Atlas, 2003a.

Turismo Religioso: ensaios e reflexões. São Paulo: Ed. Alínea, 2003b. 
FRACASSO, F. A. O desafio de Deus: amar como Ele amou - A resposta do homem: ser como ele é. Petrópolis, RJ: Vozes, 1997.

G1, Globo. Economia e Negócios - Turismo religioso estimula economia de mais de 300 cidades do país. 18/09/2010. Disponível em: <http://g1.globo.com/economia-enegocios/noticia/2010/09/turismo-religioso-estimula-economia-de-mais-de-300cidades-do-pais.html>. Acesso em: 6/12/ 2011.

GILMORE, J. H.; PINE II, B. J. Autenticidade: Tudo que os consumidores realmente querem. Rio de Janeiro: Elsevier, 2008.

GOMES, C.; PINTO, L. Lazer na América Latina / Tiempo Libre, Ocio Y Recreación En Latinoamérica. 2. ed. Belo Horizonte: UFMG, 2009.

GOMES, P. M. Ecoturismo: uma (re) leitura dos discursos. Universidade de Brasília UnB. Centro de desenvolvimento sustentável. Brasília-DF: Julho/2000.

KRIPPENDORF, J. Sociologia do turismo: para uma nova compreensão do lazer e das viagens. São Paulo: Aleph, 2000.

LIBANIO, J. B. Qual é o caminho entre o crer e o amar? São Paulo: Paulus, 2005.

MICHAELIS, dicionário. Disponível em:

$<$ http://michaelis.uol.com.br/moderno/portugues/index.php?lingua=portugues-

portugues\&palavra=região>. (Português Brasil). Acesso em: 02/01/2012.

MOLINA, S. O Pós-Turismo. São Paulo: Aleph, 2003.

OLIVEIRA, C. D. M. Turismo Religioso: uma breve apresentação. Etur: 2006. Disponível em:

$<$ http://www.etur.com.br/conteudocompleto.asp?idconteudo=10012>. Acesso em: 05/01/12

PALMA, J. Romeiro ou Peregrino? Via Peregrina. 2009. Disponível em: <http://www.viaperegrina.com.br/home/romeiro-ou-peregrino/>. Acesso em: 02/03/12.

PELLEGRINI, L. Os pés alados de Mercúrio: relatos de viagens à procura do self. São Paulo: Axis Mundi, 1997.

PÉREZ, X. P. Turismo Cultural: Uma visão antropológica. Colección PASOS edita, n. 2. 2009. Disponível em:

<http://www.pasosonline.org/Publicados/pasosoedita/PSEdita2.pdf>. Acesso em: $15 / 03 / 12$

PORTAL TURISMO RELIGIOSO, 2012. Disponível em:

$<$ Turismo

Religioso.

http://www.turismoreligioso.org.br/?system=news\&action=read\&id=219>. Acesso em: $06 / 12 / 12$. 
RIBEIRO, C. Turismo religioso: fé, consumo e mercado. E-Revista Facitec, v. 5, n. 1, Art. 6, ago.-dez. 2010.

RIBEIRO, H. Andar com fé e o sentido do chegar. Caderno Virtual de Turismo. V. 3, n. 1 (2003).

$\begin{array}{lllll}\text { SEBRAE. } & \text { Circuito } & \text { Turístico } & \text { Religioso. } & 2013 .\end{array}$ http://www.sebraesp.com.br/PortalSebraeSP/Vitrine/NegociosTuristicos/CircuitoReligi oso/Documents/circuito_religioso_municipios.pdf>. Acesso em: 06/12/11.

SERRANO, D. P. Teoria de Maslow - A Pirâmide de Maslow. 2011. Disponível em: <http://www.portaldomarketing.com.br/Artigos/maslow.htm>. Acesso em: 24/03/12.

SILVA, Renata. O turismo Religioso e as transformações socioculturais, econômicas e ambientais em Nova Trento - SC. 2004. Disponível em: http://www6.univali.br/tede/tde_arquivos/2/TDE-2005-12-16T074347Z-

17/Publico/Renata\%20Silva_parte\%201.pdf. Acesso em: 07 de janeiro de 2012.

STEIL, C A. Romeiros e turistas no santuário de Bom Jesus da Lapa. Universidade Federal do Rio Grande do Sul - Brasil. v. 9 n. 20, Porto Alegre, Out. 2003. Disponível em:

<http://www.scielo.br/scielo.php?pid=S0104-

$71832003000200013 \&$ script=sci_arttext $>$. Acesso em: 02/03/2012.

TURISMO RELIGIOSO. Roteiros - Com fé na bagagem. 2010. Disponível em: <http://www.turismoreligioso.org.br/?system=news\&action=read\&id=189>. Acesso em: $06 / 12 / 11$.

WEARING, S; NEIL, J. Ecoturismo - Impactos, Potencialidades e Possibilidades. Barueri, SP: Manole, 2001.

Recebido em: 30-04-2013.

Aprovado em: 29-05-2013. 